\title{
Ethological Investigations on a Herd of Plains Zebra in a Safari Park: Time-Budgets, Reproduction and Food Competition
}

\author{
MATTHIJS B.H. SCHILDER and PIETER L. BOER \\ Laboratory for Comparative Physiology, State University of Utrecht, and Burgers' Zoo, Arnhem \\ (The Netherlands)
}

(Accepted for publication 26 June 1986)

\begin{abstract}
Schilder, M.B.H. and Boer, P.L., 1987. Ethological investigations on a herd of plains zebra in a safari park: time-budgets, reproduction and food competition. Appl. Anim. Behav. Sci., 18: 45-56.

The social organization of a herd of 25 plains zebras under safari park conditions and the timebudgets of 18 individuals from this herd were investigated. The zebras had organized themselves in harem groups. Stallions appeared to spend more time acting socially than did other sex-age classes and they spent less time feeding. Social behaviours were mainly directed against other stallions. Stallions were also more on the alert. The time-budget of safari park zebras largely agrees with that of their wild counterparts. From data on time budgets and from differences in the reproductive output of adults of different ranks it is concluded that differential access to food plays an important role in the safari park.
\end{abstract}

\section{INTRODUCTION}

A herd of plains zebra has been kept in Burgers' Zoo safari park at Arnhem, The Netherlands, since the late 1960's. Ethological investigations of communication (see Schilder et al., 1984), social behaviour and social organization were carried out here in 1974-75 and from 1979 until the present time. From an educational and behavioural point of view, it is desirable to keep the animals in a way that permits them to behave as naturally as possible and to form natural social units. To achieve this, a reasonably large herd including some adult stallions has been kept. This appeared to be possible without the occurrence of excessive fighting. The next problem was to establish whether the individuals had grouped themselves into natural units and to find out to what degree their behaviour resembled that of wild zebras. As obviously not enough grass was available, artificial feeding was necessary. The method of providing 
food could well have consequences upon the behaviour of the zebras, especially on the level of aggression. In this paper, we shall present data on group-composition, time-budgets and reproduction of our plains zebras, and compare our data with those that Klingel (1967) collected for wild plains zebra. We expected the time-budgets of the harem stallions to differ from those of the other zebras, as stallions perform activities concerning the maintenance of their harem. This includes being alert, performing herding activities and keeping out competitors. Harem stallions were therefore expected to spend much more time acting socially, performing associated locomotion and being alert than other sex-age classes, especially the mares. The latter were expected to give priority to feeding behaviour. Because of the above reasons, feeding stallions were expected to experience more disturbances than other sex-age classes. With regard to reproduction, it has been argued that males are the more expensive sex to produce (Clutton-Brock and Guinness, 1981). Data have been presented for horses which support this view (Rophia et al., 1969, cit. in Waring, 1983; Duncan et al., 1984), and our research provided some indications that the same could hold for plains zebra. Trivers and Willard (1973) proposed that females should produce a higher proportion of male offspring when they are healthiest because male offspring will then become good competitors and consequently also good reproducers. When there is greater competition for food, there should be a relationship between a mare's rank and her reproductive success, and also between her rank and the sex of her offspring.

\section{MATERIALS AND METHODS}

\section{The zebra herd, its enclosure and stabling}

Over the last few years, the zebra herd has consisted of $4-5$ adult stallions, 7-10 adult mares and their offspring; 23-29 animals in all. They are Grant and Chapman zebra (Equus quagga boehmi and Equus quagga antiquorum) and intermediates between the two sub-species. The zebra live in an open woodland area of $16 \mathrm{ha}$, together with several other species normally living together on African plains. Twice a day the animals are fed hay on 2-3 different points in the feeding area. In addition, felled trees are frequently provided and the zebras eat the leaves and the bark. Pelleted food is distributed once a day on the feeding area. Every night all animals are stabled; the stallions alone in boxes, the mares with foals together in boxes. Some groups of mutually tolerant zebra are stabled together in larger stables. In the stable, the zebras are given additional pelleted food.

\section{Methods}

Data on time-budgets were collected from September to December 1983. The animals were observed by car during 38 sessions of $3 \mathrm{~h}$ on each observation 
day. We used a time-sampling observation method. Every $7.5 \mathrm{~min}$, the behaviour of 18 of the then 26 zebras was sampled. These 18 zebras included the 4 stallions, 7 of the mares and 7 of the foals and yearlings. The order in which the individuals were observed was changed every day. For each individual, the sampling moments were spread equally between 09.00 and $17.00 \mathrm{~h}$. A number of relevant behaviours used in the sampling procedure were later classified into 4 categories resembling those used by Boy and Duncan (1979) and Klingel (1967).

(1) Foraging. Feeding on hay, grazing, drinking water and eating bark.

(2) Orientation and movement. Walking, trotting, galloping, rolling, rubbing against a tree, standing with 'attention face' ( Schilder et al., 1984), autoplay, autogrooming, defecating and urinating.

(3) Social. All behaviours directed towards conspecifics. Individual recipients of social behaviours were also noted.

(4) Resting. Standing in a resting position, lying flat, lying up and standing, without performing any of the other behaviours mentioned above.

The number of samples per zebra varied between 726 and 830 . For each individual, the proportion of the total observations occupied by each behaviour was expressed as a percentage of that total. The results are shown in Table I. In this table, behaviours belonging to the category "orientation and movement" which were performed in a social context were grouped in the category "social". The individuals were lumped into 3 sex-age classes: (1) adult stallions; (2) adult mares; (3) foals and sub-adults. Mares were considered to be adult when 2.5 years of age or older. For comparisons between sex-age classes, the Mann-Whitney $U$ (MWU) test (Siegel, 1956) was applied. If insufficient individuals were involved in the performance of a particular behaviour to allow the use of this test, the Wilcoxon matched pairs signed ranks (WMP) test (Siegel, 1956) was applied, comparing the rows of daily values for the behaviour under discussion for the individuals. For comparisons between data within a certain sex-age class, sampled in two different circumstances, the WMP test was also used. The spatial structure (e.g. group membership) was established by analysis of adjusted residuals (Everitt, 1977) of a matrix of proximity scores. Dominance relationships within the harems were established every half-year by using the method of Schein and Fohrman (1955) on data on avoidance behaviour. The dominance hierarchy in the stallions was established in essentially the same way (M.B.H. Schilder, in preparation). For the purpose of this study, we distinguish for each harem with two mares a highest ranking mare and a lowest ranking mare. When more than two mares are present, the others are considered to be middle-ranking mares. The same categories have been distinguished for the adult stallions. The hypotheses concerning the relationship between reproductive output and dominance rank were tested as follows: the reproductive output of highest- and lowest-ranking mares was compared using the Mann-Whitney $U$-test, involving only (potentially) reproductive 


\section{TABLE I}

Time-budgets of all individuals in percentages of the total number of samples for each individual ${ }^{1}$

\begin{tabular}{|c|c|c|c|c|c|c|c|c|c|c|c|}
\hline \multirow{2}{*}{$\begin{array}{l}\text { Behavioural } \\
\text { categories }\end{array}$} & \multicolumn{4}{|c|}{ Stallions } & \multicolumn{7}{|c|}{ Mares } \\
\hline & $\mathbf{K}$ & $\mathrm{S}$ & $\mathrm{F}$ & G & $\mathrm{s}$ & $\mathrm{P}$ & 0 & $\mathbf{E}$ & $\mathrm{L}$ & $\mathrm{T}$ & $\mathrm{c}$ \\
\hline Social & 7.0 & 16.1 & 15.2 & 10.2 & 3.6 & 3.6 & 2.0 & 3.3 & 0.6 & 1.2 & 1.1 \\
\hline Resting & 13.3 & 10.5 & 9.0 & 10.6 & 16.8 & 13.6 & 15.7 & 12.9 & 27.6 & 20.8 & 20.2 \\
\hline \multicolumn{12}{|l|}{ Orientation } \\
\hline movement & 29.4 & 22.4 & 25.8 & 23.9 & 23.3 & 22.8 & 19.7 & 21.7 & 16.9 & 15.7 & 15.2 \\
\hline Eating hay & 22.1 & 36.5 & 35.6 & 37.8 & 21.4 & 26.7 & 43.5 & 44.4 & 41.8 & 44.0 & 44.0 \\
\hline Grazing & 27.6 & 13.6 & 12.4 & 16.9 & 34.4 & 32.1 & 18.6 & 16.9 & 10.3 & 15.2 & 17.1 \\
\hline Foraging & 50.3 & 51.0 & 50.0 & 55.3 & 56.3 & 60.0 & 62.6 & 62.1 & 54.8 & 62.3 & 63.5 \\
\hline
\end{tabular}

'Column on far right: time-budget of wild plains zebra. Data of the latter extracted from Klingel (1967) . ST $=$ stallions; $\mathrm{MA}=$ mares; $\mathrm{FO}=$ foals; $\mathrm{TOT}=$ total.

\begin{tabular}{|c|c|c|c|c|c|c|c|c|c|c|c|}
\hline \multicolumn{7}{|c|}{ Foals } & \multirow[t]{2}{*}{$\mathrm{ST}$} & \multirow[t]{2}{*}{ MA } & \multirow[t]{2}{*}{ FO } & \multirow[t]{2}{*}{ TOT } & \multirow[t]{2}{*}{ Africa } \\
\hline$Q$ & A & $\mathrm{Y}$ & $\mathbf{J}$ & B & $\mathrm{X}$ & $\mathrm{R}$ & & & & & \\
\hline 4.3 & 3.7 & 2.4 & 2.8 & 1.6 & 2.3 & 2.4 & 12.1 & 2.1 & 2.7 & 4.7 & - \\
\hline 34.4 & 15.1 & 20.5 & 12.1 & 21.8 & 17.0 & 17.6 & 10.8 & 18.4 & 19.7 & 17.1 & 18.6 \\
\hline 29.2 & 21.7 & 25.1 & 21.7 & 18.9 & 18.4 & 19.1 & 25.4 & 19.3 & 21.9 & 21.7 & 21.4 \\
\hline 14.5 & 29.6 & 37.1 & 43.7 & 41.6 & 43.1 & 42.8 & 33.1 & 37.8 & 36.5 & 36.2 & - \\
\hline 16.5 & 28.6 & 14.1 & 18.9 & 14.5 & 17.6 & 16.6 & 17.6 & 20.8 & 17.9 & 19.0 & 60.0 \\
\hline 32.1 & 59.4 & 52.0 & 63.4 & 57.7 & 62.3 & 60.9 & 51.7 & 60.2 & 55.7 & 56.5 & 60.0 \\
\hline
\end{tabular}

mares. For the stallions this was not possible, and here the total output of highest-ranking stallions was tested against the total output of lowest-ranking stallions by means of the $\chi^{2}$ test. Differences concerning the production of male offspring between highest- and lowest-ranking individuals were tested by comparing the pooled outputs of individuals by means of the Fisher Exact Probability test (Siegel, 1956). All tests were 1-tailed if specific hypotheses were tested and 2-tailed if such was not the case.

\section{RESULTS}

\section{The overall social structure of the herd}

In the second half of 1983 , when the time-budget study was performed, the herd consisted of 4 harems and 2 small groups. One small group consisted of 2 young females which wandered about independently (see Fig. 1). A second group of 2 foals ( $X$ and $R$ ) also operated more or less independently of their 


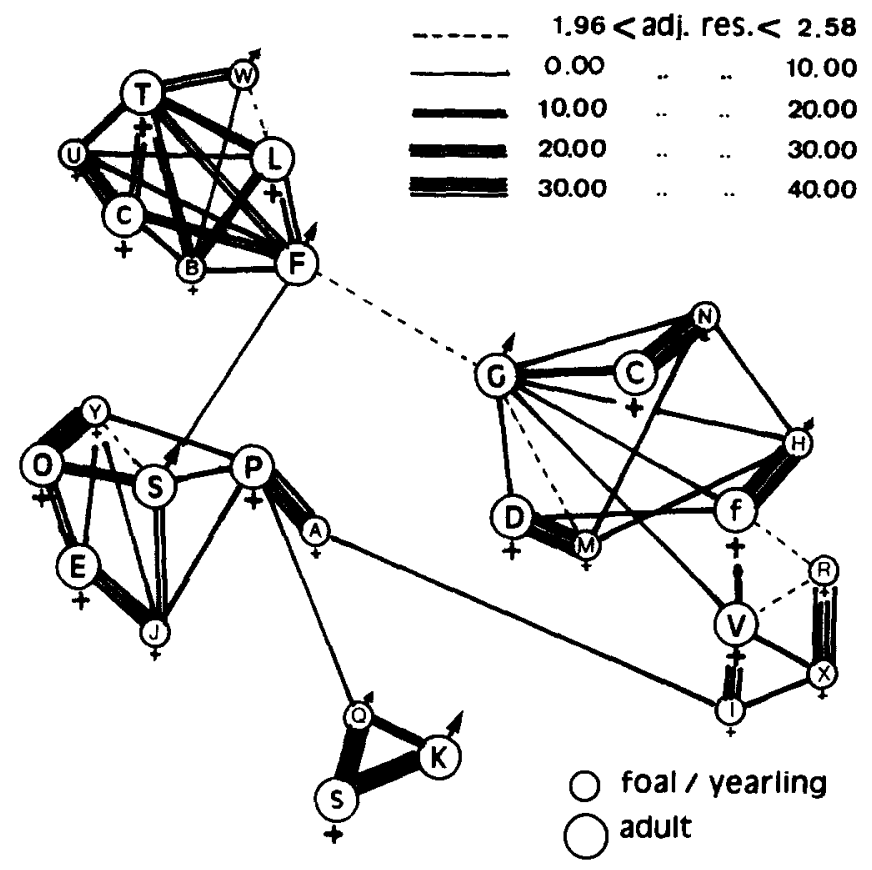

Fig. 1. Spatial organization of the Arnhem zebra herd during the second half of 1983, based on nearest-neighbour scores. The values of the adjusted residuals indicate the strength of spatial associations. Only statistically significant proximity scores are shown. Broken lines, $0.01<P<0.05$; solid lines, $P<0.01$.

natal harem, G. Within each harem there was a linear hierarchy, the stallion being at the top. Positive social bonds and mutual tolerance were demonstrated by close proximity and positive social interactions like grooming, play and rubbing. In 1983 it was clear that there were 2 top stallions, about equal in rank, and 2 low-ranking stallions, also about equal in rank. In other years the stallions could be ranked in a (nearly) linear hierarchy.

\section{Time-budgets}

The time-budgets of the individuals as well as of the sex-age classes are shown in Table I. Table II summarizes the significant differences between the animal classes in the performance of 4 main behavioural categories and several sub-categories. The stallions spent more than four times as much of their time on social interactions than did the mares or foals. Almost two-thirds of the stallions' social interactions were with other stallions, $1 \%$ of the time was spent on herding behaviour. The time that the stallions spent on social behaviour remained fairly stable throughout the day. The time they spent on performing challenge rituals ("greeting" c.f. Klingel, 1967) remained at about 5\% in each 
TABLE II

Some differences between time-budgets of sex-age classes

\begin{tabular}{llll}
\hline & $\mathrm{ST} / \mathrm{M}$ & $\mathrm{ST} / \mathrm{F}$ & $\mathrm{M} / \mathrm{F}$ \\
\hline Foraging & $<P<0.01$ & - & - \\
& & & - \\
Orientation/movement & $>P<0.01$ & $>P<0.01$ & - \\
$\quad$ Standing at attention & $>P<0.01$ & $>P<0.01$ & - \\
$\quad$ Galloping and & & & - \\
trotting & - & - & $<P<0.05$ \\
All locomotion & $<P<0.01$ & $<P<0.01$ & - \\
Resting & $>P<0.01$ & $>P<0.01$ & $>P<0.05$ \\
Social behaviour & $>P<0.01$ & $>P<0.01$ & $<P<0.05$ \\
$\quad$ Directed at stallions & $>P<0.01$ & - & - \\
$\quad$ Directed at mares & - & & \\
Directed at foals & & & \\
\hline
\end{tabular}

Data from Table I, tested with Mann-Whitney $U$-test, 1-tailed. Blank scores: no significant differences. ST = stallion; $M=$ mare; $F=$ Foal.

hour. Furthermore, the stallions grazed and fed on hay significantly less than did mares or foals. Comparing the time spent eating compared to grazing by highest- and lowest-ranking adults, it appears that low-ranking stallion $\mathrm{K}$ spent less time eating than the 3 other stallions (WMP test, $P=0.0001$ ), but he grazed more (WMP test, $P=0.001$ ). In one harem, the lowest-ranking mare spent less time eating but more time grazing than the highest-ranking mare (WMP test, $P<0.01$ in both tests). In another harem, the time spent eating did not differ significantly between the highest- and the lowest-ranking mare, but the latter spent more time grazing than did the former (WMP test, $P<0.01$ ). For the mares of stallion G (not included here), we have data sampled previously which do not suggest a relationship between rank and time spent grazing or eating hay. In order to investigate how "being alert" and other disturbances interfere with foraging, we present the samples for an individual containing "feeding on hay" on a time basis (Fig. 2). These then produce "feed runs", a run length being defined as a row of uninterrupted scores of eating hay. The average length of such runs will decrease with increasing interruptions during feeding. The frequency of feeding runs of all lengths was analysed for all sex-age classes, and results are presented in Fig. 3. Stallions did feed more frequently in shorter runs than the mares (MWU test, $P=0.036$ ); they also fed less frequently in longer feeding runs ( $M W U$ test, $P=0.05$ ). The mean run lengths for the mares were 1.5 times as long as those for the stallions (MWU test, $P=0.025$ ). Mean run lengths of the foals were not statistically different from those for the stallions or the mares, although stallions tended to feed in 


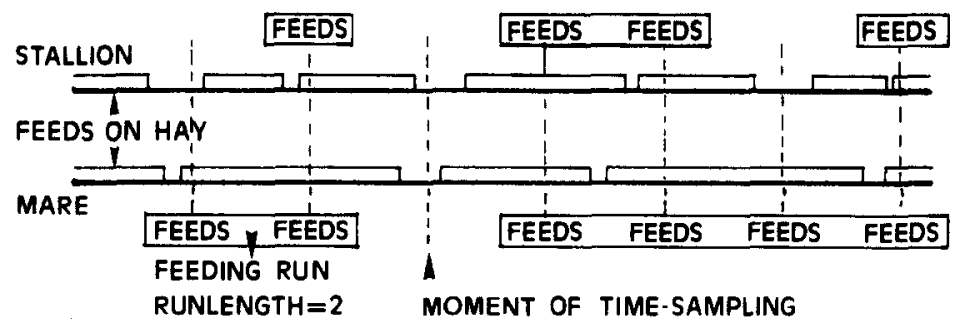

Fig. 2. Schematic representation of the method to estimate length differences of eating bouts from time-sampling data. Time-sampling moments are indicated by broken lines. The stallion's scores: run-length 1, twice; run-length 2, once. The mare's scores: run-lengths 2 and 4 , once each. Average run-length in this example is 1.4 for the stallion and 3.0 for the mare.

shorter runs than foals ( $M W U$ test, $P=0.082$ ). Both lower-ranking stallions ( $\mathrm{K}$ and $\mathrm{S}$ ) had slightly shorter average run-lengths than the two higher-ranking stallions; mares from Harem $\mathrm{K}$ had the shortest average run-length of all adult mares. In Harem $S$, the average run-length of the lowest-ranking adult mare was shorter than those of the other resident mares, but such was not the case in Harem F. So a tendency for lower ranking individuals to experience more disturbances seems to exist. An identical analysis of the run-lengths of grazing did not show any significant differences between the sex-age classes.

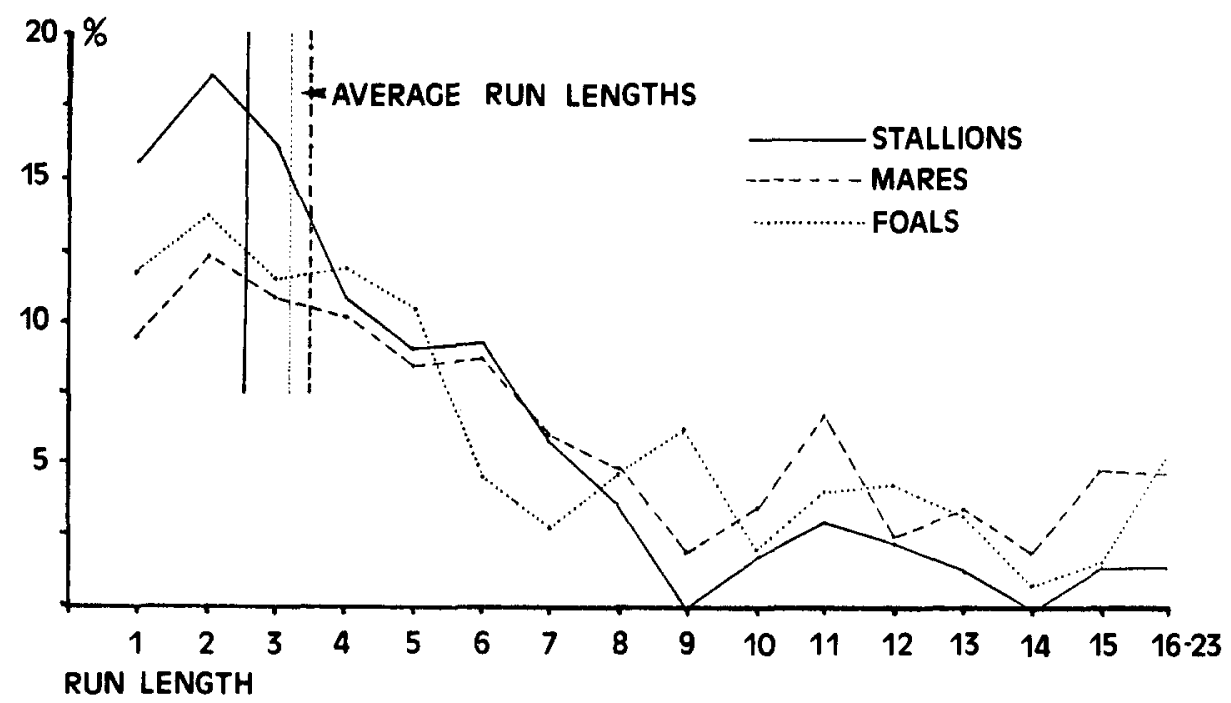

Fig. 3. Feeding run-lengths (horizontal) plotted against the percentage of feeding scores falling in each run-length. Run-length classes $16-23$ are represented by average values for each sex-age class. 
TABLE III

Reproductive success of mares and stallions of different ranks ${ }^{1}$

\begin{tabular}{|c|c|c|c|c|c|c|c|c|c|c|}
\hline & Arnhem & & & & & & Wild & & & \\
\hline $\begin{array}{l}\text { No. foals } \\
\text { Sex } \\
\%\end{array}$ & $\begin{array}{l}44 \\
17 \mathrm{~m} \\
40\end{array}$ & $\begin{array}{l}26 \mathrm{f} \\
60\end{array}$ & $1 ?$ & & & 46 & $\begin{array}{l}170 \\
74 \mathrm{~m} \\
54\end{array}$ & $87 \mathrm{f}$ & $9 ?$ & \\
\hline \multicolumn{11}{|l|}{ Arnhem } \\
\hline Rank of mother & Highest & & & Middle & & & Lowest & & & Unknown \\
\hline No. offspring & 16 & & & $15(4+)$ & & & $11(2+)$ & & & 7 \\
\hline Sex of offspring & $8 \mathrm{~m}$ & $8 \mathrm{f}$ & & $\begin{array}{l}5 \mathrm{~m} \\
(3+)\end{array}$ & $9 \mathrm{f}$ & $\begin{array}{l}1 ? \\
(+)\end{array}$ & $\begin{array}{l}4 \mathrm{~m} \\
(2+)\end{array}$ & $7 \mathrm{f}$ & & \\
\hline Rank of father & Highest & & & Middle & & & Lowest & & & Unknown \\
\hline No. offspring & 22 & & & $14(2+)$ & & & $5(1+)$ & & & 9 \\
\hline Sex of offspring & $\begin{array}{l}(3+) \\
13 \mathrm{~m}\end{array}$ & $\begin{array}{l}9 \mathrm{f} \\
(2+)\end{array}$ & $\begin{array}{l}1 ? \\
(+)\end{array}$ & $\begin{array}{l}5 \mathrm{~m} \\
(1+)\end{array}$ & $\begin{array}{l}9 \mathrm{f} \\
(+)\end{array}$ & $1 ?$ & - & $4 \mathrm{f}$ & $\begin{array}{l}1 ? \\
(+)\end{array}$ & \\
\hline
\end{tabular}

Individual contributions of highest- and lowest-ranking stallions and mares

\begin{tabular}{|c|c|c|c|c|c|c|c|c|c|}
\hline \multicolumn{5}{|l|}{ Mares } & \multicolumn{5}{|l|}{ Stallions } \\
\hline \multirow{2}{*}{$\begin{array}{l}\text { Highest } \\
\text { individual } \\
\mathrm{F}\end{array}$} & \multicolumn{2}{|c|}{ Offspring } & \multirow{2}{*}{$\begin{array}{l}\begin{array}{l}\text { Lowest } \\
\text { individual }\end{array} \\
\mathrm{T}\end{array}$} & \multirow{2}{*}{$\begin{array}{r}\text { Offspring } \\
1 \mathrm{f}\end{array}$} & \multirow{2}{*}{$\begin{array}{l}\begin{array}{l}\text { Highest } \\
\text { individual }\end{array} \\
\mathrm{E}\end{array}$} & \multicolumn{2}{|c|}{ Offspring } & \multirow{2}{*}{$\begin{array}{l}\begin{array}{l}\text { Lowest } \\
\text { individual }\end{array} \\
\mathrm{O}\end{array}$} & Offspring \\
\hline & $3 \mathrm{~m}$ & $1 \mathrm{f}$ & & & & $1 \mathrm{~m}$ & $2 \mathrm{f}$ & & $1 \mathrm{f}$ \\
\hline 0 & $3 \mathrm{~m}$ & $4 \mathrm{f}$ & 0 & $1 \mathrm{~m}$ & $M$ & $2 \mathrm{~m}$ & $2 \mathrm{f}$ & $\mathrm{K}$ & $2 \mathrm{f}$ \\
\hline $\mathrm{C}$ & $2 \mathrm{~m}$ & $2 \mathrm{f}$ & $\mathrm{C}$ & $1 \mathrm{~m}$ & F & $2 \mathrm{~m}$ & $3 \mathrm{f}$ & $\mathrm{S}$ & $1 \mathrm{f}$ \\
\hline \multirow{5}{*}{ L } & & $1 \mathrm{f}$ & $\mathrm{L}$ & $1 \mathrm{f}$ & $\mathrm{G}$ & $5 \mathrm{~m}$ & $5 \mathrm{f}$ & & \\
\hline & & & $\mathbf{M}$ & $2 \mathrm{f}$ & & & & & \\
\hline & & & $\mathrm{c}$ & $1 \mathrm{f}$ & & & & & \\
\hline & & & $\mathrm{V}$ & $1 \mathrm{f}$ & & & & & \\
\hline & & & $\mathrm{P}$ & $1 \mathrm{f}$ & & & & & \\
\hline
\end{tabular}

'The Arnhem data in the upper and lower parts of the table concern surviving foals only. Foals that died within 1 week of birth are indicated by $+. \mathrm{f}=$ female foal; $\mathrm{m}=$ male foal; $?=$ sex unknown. Data for wild zebra from Klingel (1965).

\section{Reproduction}

Table III shows reproductive success in the safari park. The sex-ratio at birth is biased more in the female direction than is the case in Africa (see Klingel, 1965; Berger, 1983). The difference is not significant. Also the sexratio at birth does not deviate significantly from a $50-50$ ratio. When the reproductive output of the adults is related to their dominance rank, it appears that the highest-ranking mares produced more surviving offspring than the lowestranking mares (MWU test, $P=0.05$ ). The highest-ranking mares tended to 
produce in total more surviving male offspring than did the lowest-ranking mares (Fisher exact probability test, n.s.). The highest-ranking stallions also produced more surviving offspring than did the lowest-ranking ones (Binominal test, $P=0.008$ ), the former also produced more male offspring than the latter (Fisher exact probability test, $P<0.05$ ).

\section{DISCUSSION}

A comparison of the data gathered in the Arnhem safari park with those from Klingel $(1965,1967,1969)$ reveals similarities as well as differences. It is important to note that under safari-park conditions a zebra herd can organize itself in natural units, but that certain deviations from the pattern reported for the wild occur. The gross social organization in the safari park is a harem structure, as is also the case in Africa. Other forms of social units known from Klingel's descriptions also occurred at Arnhem, e.g. solitary stallions and stallion groups, but small groups of youngsters, occurring regularly in Arnhem, are not described by Klingel. Their existence in the safari park might be an artefact, possibly due to the fact that young animals that have left their natal group did not have many alternative groups to join. The finding that many of the foals born in Arnhem were forced out of their natal group was also not reported for the wild situation, and is likely to be related to safari-park conditions.

Comparison of the time-budget of the safari park zebra herd with that of wild zebra (Klingel, 1967) is complicated by the fact that the method of data sampling differed. Unlike us, Klingel separately recorded the number of zebras which were feeding, standing, lying down or wandering. In his Fig. 26, which was our standard of comparison, he used data of only 1 day. If we assume that he has chosen a representative day and if we accept the difference between the sampling methods, comparison reveals that the time-budgets are almost identical. Unfortunately, Klingel did not include social behaviour in his analysis of activities, so it is impossible to verify our expectation that in the safari-park zebras spend more time interacting socially than in the wild.

Our results reveal a differentiation between the time-budgets of the stallions and the mares; the stallions were much more involved in social interactions and were more on the alert. This is in line with our expectations concerning their role in maintaining harem integrity. On the same grounds, we expected them to show more locomotor activity than did the mares. The differences found, however, were not significant. The study has provided evidence that concentrated, artificial feeding leads to differential access to food. The behaviour of the animals at the feeding places suggests that for this differential access to food, intolerance related to proximity is a more important causal factor than direct competition for food. The intolerance can in the first place be attributed to stallion behaviour related to the maintenance of harem integrity, and secondly to agonism within the harems, caused by violation of "personal spaces". Stallions, especially lower-ranking ones, tended to threaten their mare (s) away from the feeding areas when another stallion was present. Consequently, the 
mares concerned frequently had to eat what the others had left; hay of lower quality polluted by excrement. All this may well have accounted for the deteriorated condition of the only mare of stallion $\mathrm{K}$, which may in turn have resulted in the production of only 2 surviving foals during her 7 years of reproductive life. This suggests that the reproductive output of a mare belonging to a low-ranking stallion may be influenced by the relationships between stallions.

The facts that (1) highest-ranking mares produced more offspring than did lowest-ranking mares, (2) the former produced more sons than the latter, (3) the same tendencies also apply to males, (4) the "more expensive" sex to produce is produced relatively less frequently than in the wild, and (5) in years with a high population density (13-14 adults, 23-29 individuals) male foals were relatively less frequently produced ( 5 out of 20 foals were males) than during years with a low population density (6-10 adults, maximum 17 individuals, 6 foals out of 13 were males) are strong indications that differential access to provided food plays an important role in the safari park. The first two points suggest not only that relationships between adult stallions are involved, but also that within the harems the highest-ranking mare has more access to food than the lowest-ranking one. The results of the time-budget study support this view. The results are in line with our expectations and confirm ideas from Trivers and Willard (1973) and from Clutton-Brock and Guinness (1981) and Clutton-Brock and Albon (1982). Additionally, the overall food supply is not believed to be inadequate. We also tend to relate the existence of a dominance hierarchy between the harem stallions to the feeding situation. This phenomenon, like the occurrence of expulsion behaviour, seems to be peculiar to the safari-park conditions. All this suggests that the feeding situation in safaripark conditions deserves particular attention, not because zebras are inclined to show food competition, but because the spatial constraints imposed on them affect their social relationships. Finally, we do not believe that the stress, which the zebras experience under the conditions mentioned influences other aspects of their behaviour negatively, since play and grooming occur frequently, involving all sex-age classes. Neither is there evidence that absolute levels of reproduction were influenced negatively, as the birth rate in our safari park ( 41 surviving foals per 63 mare-reproduction-years, $=0.65$ foals per mare per year) is of the same magnitude as, if not slightly better than, that found by Klingel (1965) ( 0.5 foals per mare per year).

\section{CONCLUSIONS}

Under safari-park conditions, a zebra herd containing some adult stallions can organize itself in natural units. The time-budgets of safari-park zebras strongly resemble those found in Africa but, as has been outlined above, the results of comparisons should be approached with some caution. The data on reproduction suggest that the safari-park conditions influence the zebras in 
such a way that reproductive outputs are different for individuals of different social rank, and that the sex-ratio at birth is biased more in the female direction than is the case in Africa. It is likely that the proximate factor is social stress caused by the method of food provision, which forces the zebras to eat very close to one another. From a management point of view, it is of interest to note that the present method of food provision results in more female offspring being produced than male offspring. This could be considered to be a favourable effect if it appears to be difficult to find a destination for male offspring. If a more equal sex ratio is desirable, then food should be provided in a more dispersed manner, and perhaps the amount of food should also be slightly increased. Safari-park conditions lead to frequent interactions between individuals, including behaviours related to the maintenance of harem integrity, which are not released as easily under wild conditions. For the study of these and other processes of regulation of the social system, the present conditions are favourable. Therefore, the safari-park situation can shed light on the mechanisms underlying social organization in zebra herds.

\section{ACKNOWLEDGEMENTS}

This study is part of a research project of the University of Utrecht. The authors wish to thank the directorate of Burgers' Zoo for making this project possible and for providing the necessary facilities. We also thank Mr. Boer for providing a car and Prof. Dr. J.A.R.A.M. van Hooff, Dr. J.B. Wensing, Dr. G. Moran and anonymous referees for making useful comments on the manuscript. Finally we thank S.M. McNab for making linguistic improvements.

\section{REFERENCES}

Berger, J., 1983. Predation, sex ratios and male competition in equids (Mammalia: Perisodactyla ). J. Zool., London, 201: 205-216.

Boy, V. and Duncan, P., 1979. Time-budgets of Camargue horses. I. Developmental changes in the time-budgets of foals. Behaviour, 71: 187-202.

Clutton-Brock, T.H. and Albon, S.D., 1982. Parental investment in male and female offspring in mammals. In: King's College Sociobiology Group (Editors), Current Problems in Sociobiology. Cambridge University Press, Cambridge.

Clutton-Brock, T.H. and Guinness, F.G., 1981. Parental investment in male and female offspring in polygynous mammals. Nature (London), 289: 287-289.

Duncan, P., Harvey, P.H. and Wells, S.M., 1984. On lactation and associated behaviour in a natural herd of horses. Anim. Behav., 32: 255-263.

Everitt, B.S., 1977. The Analysis of Contingency Tables. Chapman and Hall, London.

Klingel, H., 1965. Notes on the biology of the plains zebra Equus quagga boehmi matschie. E. Afr. Wildl. J., 3: 86-88.

Klingel, H., 1967. Soziale Organisation und Verhalten Freilebender Steppenzebras. Z. Tierpsychol., 24: 580-624. 
Klingel, H., 1969. Reproduction in the plains zebra Equus burchelli boehmi: behaviour and ecological factors. J. Reprod. Fertil., Suppl. 6: 339-345.

Rophia, R.T., Matthews, R.G., Butterfield, R.M., Moss, F.P. and McFadden, W.J., 1969. The duration of pregnancy in thoroughbred mares. Vet. Rec., 84: 552-555.

Schein, M.W. and Forhman, M.W., 1955. Social dominance relationships in a herd of dairy cattle. Br. J. Anim. Behav., 3: 45-55.

Schilder, M.B.H., van Hooff, J.A.R.A.M., van Geer-Plesman, C.J. and Wensing, J.B., 1984. A quantitative analysis of facial expressions in the plains zebra. Z. Tierpsychol., 66: 11-32.

Siegel, S., 1956. Non-parametric Statistics. McGraw-Hill International, Tokyo.

Trivers, R.L. and Willard, D.E., 1973. Natural Selection of parental ability to vary the sex ratio of offspring. Science, 197: 287-289.

Waring, G.H., 1983. Horse Behavior. Noyes, Park Ridge, NJ. 